\title{
Poderes locais, habitação, espaços públicos e acolhimento dos que vêm de fora
}

\author{
Ana Paula Soares Carvalho \\ Professora do Departamento de Ciências Sociais | PUC-Rio \\ Contato: apcarvallho@gmail.com
}

\section{RESUMO}

A concentração de atividades financeiras, administrativas, científicas em algumas cidades levou ao acúmulo de oportunidades em locais com características específicas, que se tornaram polo de atração de pessoas do mundo inteiro. É comum a esses locais a crise na oferta de habitação a preços acessíveis. Não raro, os mais duramente atingidos por essa crise são imigrantes e refugiados. Acesso ao trabalho é outra questão fulcral para essas pessoas, especialmente aquelas sem permissão para trabalhar. Este ensaio tem como objetivos refletir sobre esse processo e explorar as possibilidades que governos locais/municipais têm de prover condiçóes de vida mais adequadas para habitantes que vivem essa condição específica de exclusão.

Palavras-chave: migraçóes; espaço público; trabalho; habitação.

\section{ABSTRACT}

The concentration of financial, administrative and cientific activities in a few cities led to the build-up of opportunities in places with specific characteristics, which became attraction hubs for people all over the world. Its common in these places supply crisis in the affordable dwelling market. Not obstantly, the ones more hardly affected by this crisis are immigrants and refugees. Access to jobs is also another crucial issue for this population, specially those without work permission. This essay aims to reflect on this process and explore the possibilities that local governments could provide for life conditions that are more adequate for habitants that live in this specific situation of exclusion.

Key-Words: migrations; public space; work; habitation 
A existência de fluxos migratórios intensos não é fenômeno recente. Pode-se dizer, no entanto, que a fase do capitalismo global que se inaugura por volta dos anos 1970 - cuja emergência está fortemente relacionada a inovaçóes tecnológicas que impactam as possibilidades de circulação de bens e o fluxo de capitais (HARVEY, 1996) - dá novos contornos a essas ondas migratórias. A desindustrialização de certas regiôes de países ricos, acompanhada da industrialização de certas regióes de países em desenvolvimento, e a concentração de atividades financeiras, administrativas e científicas em poucas cidades são fatores que ajudaram a produzir novas desigualdades globais e, consequentemente, alteraçóes demográficas e novas tendências de migração.

Refletindo sobre essas mudanças, Sassen (1991) argumenta que a globalização e a internacionalização da produção fizeram emergir cidades globais, que são aquelas detentoras de determinadas qualidades que as habilitam a funcionar como polos organizadores da produção no mundo. Ao se tornarem esse tipo de polo, essas cidades se transformam também em polo de atraçáo de pessoas. Atraem, por um lado, profissionais com alta qualificaçáo em busca desses postos em funçóes coordenadoras e, por outro, trabalhadores com baixa qualificação vindos de regiôes pobres no mundo, em busca dos postos de empregos em funçóes de manutençáo da roda viva dos serviços de coordenação. Buscam vagas como recepcionistas, postos em restaurantes, empresas de limpeza, construção, manutenção, entre outras várias funçôes necessárias ao funcionamento da cidade.

Algumas cidades grandes que apresentam certo dinamismo econômico e exercem influência regional, especialmente em países em desenvolvimento, embora não possam ser chamadas de cidades globais, compartilham com elas essa característica de atração de trabalhadores com variados níveis de qualificação.

Nas últimas décadas, é comum a esses polos de atração de migrantes de fora e de dentro do país apresentarem um quadro de profunda crise de oferta de habitação a preços acessíveis. Sucessivos relatórios da ONU sobre o direito à moradia adequada vêm mostrando que, tanto no norte como no sul global, cada vez mais indivíduos enfrentam problemas no acesso à moradia de custo acessível. (FARHA, 2017; ROLNIK, 2014, apud FIELDS e HOTKINSON, 2018) As despesas relativas à moradia consomem uma parte cada vez maior da renda, levando a condiçóes inadequadas de habitação e mesmo à falta completa de abrigo. Como apontam Fields e Hotkinson (2018, p.1), essa situação está em grande medida ligada ao funcionamento disfuncional e geograficamente desbalanceado dos mercados habitacionais, que leva ao deslocamento de pessoas de renda média e baixa para fora das áreas de maior valor e a uma produção limitada de unidades habitacionais com vistas a manter os preços altos.

Não raro, os mais duramente atingidos por essa crise são imigrantes e refugiados ${ }^{1}$, especialmente aqueles sem autorização para morar e/ou trabalhar no país em que se encontram. Sua situaçáo muitas vezes os impossibilita de entrar no mercado formal de habitação, forçando-os a situaçóes precárias de alojamento. Isso, por sua vez, facilita que sejam explorados por seus senhorios.

A rede de suporte a esses habitantes da cidade inclui, normalmente, instituiçôes religiosas e organizaçôes não-governamentais, com o apoio da comunidade de descendentes já estabelecida em determinado local.

O acesso ao trabalho é outra questão fulcral para refugiados e imigrantes, especialmente aqueles sem permissão para trabalhar. Mesmo nas sanctuary cities dos EUA, onde os governos locais tradicionalmente têm se negado a permitir que, em seu território, imigrantes sejam perseguidos de qualquer forma, é difícil garantir a essa população bons postos de trabalho em virtude de sua situação irregular. Nos casos em que se encontram em situação regular, as barreiras culturais e linguísticas são entraves por vezes intransponíveis quando se trata de encontrar uma boa colocaçáo no mercado de trabalho. 
É assim que nas cidades que atraem indivíduos de todo o mundo é comum ver imigrantes e refugiados trabalhando nas ruas e praças, muitas vezes na condição de camelôs ou vendendo comidas típicas de seus locais de origem. $\mathrm{O}$ espaço público das cidades funciona, assim, como local fundamental para a sobrevivência dessas populações.

De forma esquemática, pode-se dizer que neste texto se parte das seguintes ideias: algumas cidades, por concentrarem riqueza e oportunidades, atraem grandes contingentes de pessoas; em geral, nessas cidades há um déficit de habitação a preços acessíveis; alguns grupos são especialmente atingidos pela crise habitacional, como é o caso dos imigrantes e refugiados em condição irregular; indivíduos nessa situação também têm muita dificuldade em acessar bons postos de trabalho e não raro atuam como vendedores ambulantes.

Partindo dessas premissas, pretende-se neste ensaio refletir sobre essas questóes e abordar de forma exploratória as possibilidades que governos locais/municipais dessas cidades têm de prover condiçốes de vida mais adequadas aos habitantes que vivem essa condição específica de exclusão. Em geral, não é da alçada dos poderes locais garantir direitos políticos e acesso ao mercado de trabalho formal a essa populaçáo, em virtude da legislação nacional/federal, que cuida dos aspectos relacionados à cidadania e a permissóes de trabalho. Ainda assim, há formas de garantir direitos mínimos e melhorar o cotidiano desses moradores. Sáo enfocados os aspectos acima aventados: habitação e trabalho nos espaços públicos.

\section{Desafios do Morar}

Como se aventou na introdução deste texto, acolher adequadamente aqueles que buscam melhores condições de vida e trabalho em determinada cidade implica em lidar com um problema maior, que é o da habitação de qualidade, bem localizada e a preços acessíveis.

Garantir habitação adequada para as classes populares foi uma política bastante difundida nos países que adotaram alguma forma de Estado de Bem-Estar Social nas décadas imediatamente seguintes ao fim da Segunda Guerra Mundial. Em certo sentido, ganhou corpo a ideia de que a habitação é um direito social, tal como saúde, educação e seguro-desemprego. $\mathrm{O}$ Estado passou, pois, a ter papel fundamental na provisão da moradia. Linhas de crédito a juros baixos, formas distintas de aluguel com valores controlados, administrados ou não pelo Estado, foram algumas medidas adotadas. Dessa forma, parte da produção e gerenciamento das unidades habitacionais deixou de ser controlada por agentes privados.

Hoje, no entanto, mesmo em países que adotaram políticas de provisão massiva de moradia para as classes populares, há muitas cidades em que se observa um número crescente de pessoas morando em condiçóes precárias e nas ruas. Uma série de fatores faz com que, mesmo em países com tradição de provisão pública de habitação, o déficit habitacional siga crescendo. Como se mencionou anteriormente, mudanças na economia global produziram a concentração de oportunidades em algumas cidades e o esvaziamento de regiôes inteiras em países desenvolvidos e em desenvolvimento. Alguns locais que concentram ramos da economia especialmente lucrativos, como o de desenvolvimento de softwares, tornaram-se praticamente inacessíveis mesmo a famílias com nível de renda compatíveis com o que se costuma chamar de classe média. É o caso de cidades como São Francisco, Seattle e seus respectivos entornos. Cidades extremamente bem sucedidas no que tange à atração de turistas, como Barcelona, Amsterdã e, mais recentemente, Lisboa, também foram se tornando extremamente caras para seus habitantes. Quanto ao preço dos aluguéis, essa situação se agravou ainda mais com o advento de aplicativos de aluguel temporário de apartamentos, casas e quartos, como o Air Bnb. 
Não se pode esquecer que uma política falha de construção de habitaçôes na América do Norte e na Europa, que implicou em expansão desordenada do crédito imobiliário $^{2}$ e, consequentemente, em uma bolha imobiliária, está na base na crise financeira de 2008. (ALBERS, 2016) Com a crise, milhares de pessoas perderam suas casas e inúmeras propriedades ficaram vazias ou subutilizadas. Mesmo com a retomada do crescimento econômico na década de 2010, um grande contingente de pessoas segue sem condiçóes de arcar com os custos da moradia adequada.

Há ainda o corte de recursos públicos para o setor da moradia, associado ao cenário de crise do Estado do Bem-Estar Social e pressão pela adoção de medidas de austeridade fiscal. Nesse contexto, emergem experimentos de política urbana que visam transformar o espaço urbano em arena para o crescimento econômico orientado pelo mercado. No campo da política habitacional, isso implica em uma reestruturação do mercado de habitaçôes que ataca as habitaçôes públicas e outras formas de habitação com aluguel baixo, bem como formas de controles de aluguel e construçôes subsidiadas para a população de baixa renda. (BRENNER, THEODORE, 2002).

Londres talvez seja hoje a epítome da crise habitacional em cidades globais. Se na Grã-Bretanha o tema da habitação tem ocupado o centro dos debates políticos (cf. ELGOT, 2017), esse assunto está ainda mais na ordem do dia na cidade onde a média os alugueis no mercado privado supera em muito a média nas demais partes do território. A média do preço dos imóveis em Londres chega a ser o dobro da média no restante da Grã-Bretanha. (HODKINSON et al., 2016) Quando se trata do mercado de habitaçóes de luxo, entre 2005 e 2015, em nenhum lugar do mundo os preços subiram mais rapidamente que em Londres. (KNIGHT FRANK, 2015)

Nesse mercado aquecido, locadores se encontram em posição privilegiada para escolher seus inquilinos e mesmo forçá-los a se engajar em uma espécie de lei- láo de preços do aluguel. (BESWICK, 2016) Como afirmam Beswick et al. (2016), o aumento dos despejos e do número de pessoas vivendo nas ruas não deve espantar diante desse cenário.

No Brasil, as tentativas feitas no sentido de prover moradia de baixo custo às classes populares ao longo do século XX foram bastante tímidas, de modo que a provisão e gerenciamento das unidades habitacionais se deu majoritariamente por agentes privados. A autoconstrução há muito é uma saída encontrada pelas classes populares para a questáo da moradia, uma vez que raramente puderam contar com políticas estatais que fossem ao encontro de suas necessidades no âmbito da habitação. Nas grandes cidades, o efeito mais visível dessa negligência é a grande quantidade de assentamentos irregulares e favelas, bem como o espraiamento das cidades e a existência de alguns vazios urbanos em áreas bem localizadas. Assim, embora uma da população de baixa renda tenha conseguido se estabelecer em áreas nobres - como é o caso bem conhecido das favelas da zona sul da cidade do Rio de Janeiro -, a maioria desses habitantes vive em áreas distantes das regióes em que se concentram as atividades econômicas, os serviços, os aparelhos culturais, etc. Outra solução encontrada por esses habitantes sáo os cortiços que, apesar de, em geral, localizarem-se em áreas centrais, são bastante precários ${ }^{3}$.

O programa Minha Casa, Minha Vida, iniciado em 2009, além de não ter diminuído o déficit habitacional no país, acirrou ainda mais a tendência de expansão das fronteiras das cidades e regiôes metropolitanas. Apenas algumas iniciativas no âmbito desse mesmo programa - na sua versão voltada à parceria com entidades da sociedade civil ligadas à questáo da moradia popular - produziram unidades habitacionais bem localizadas no tecido urbano. (ROLNIK, et al., 2015)

É também pouco utilizado no Brasil o sistema de locação social, diferente do que ocorre em cidades europeias com forte tradição de provisão pública de ha- 
bitação. (WERNECK, SANTOS JUNIOR, 2015) Mais uma evidência de que o Estado brasileiro relega ao mercado a questão da moradia.

Assim, embora o direito à habitação conste na Constituição Brasileira, pouco se tem feito em termos de políticas públicas para a sua realização.

Essa ausência história de uma política adequada de habitação a preços acessíveis produziu um problema crônico relacionado ao déficit habitacional. E a crise da moradia popular nas grandes cidades brasileiras agravou-se ainda mais a partir de 2009. O valor dos imóveis e dos alugueis disparou em praticamente todas as capitais e grandes cidades do país. Entre os fatores que contribuíram para isso estão os grandes eventos esportivos e a maior disponibilidade de recursos para o setor imobiliário. (CASTRO, NOVAES, 2015).

De acordo com a Fundação João Pinheiro ${ }^{4}$, o déficit habitacional $^{5}$ no Brasil em 2007 era de 5.855.375 unidades. Em 2015, esse número saltou para 6.355.743. Esse déficit mede a deficiência no estoque de moradias levando em consideração: o ônus excessivo com aluguel; casas que precisam ser substituídas por estar em estado precário; e novas unidades que deveriam existir para evitar coabitação familiar e adensamento excessivo de moradores em imóveis alugados.

É importante notar que, além do aumento do déficit, houve mudanças na sua composição.

Enquanto, em 2007, cerca de 30\% do déficit correspondia ao ônus excessivo com aluguel, em 2015, esse percentual era de 50\%. Nas regióes metropolitanas do Rio de Janeiro e de São Paulo, esse percentual chegou a $66,5 \%$ e $58 \%$ respectivamente. (FUNDAÇÃO JOÁO PINHEIRO, 2018)

Para essa situação, certamente colabora a retenção especulativa de terrenos urbanos. Embora haja me- canismos legais para conter a esse tipo de prática e pressionar os proprietários a dar destino para suas propriedades, eles ainda são utilizados de forma limitada pelos municípios brasileiros. (CARVALHO, 2016) Há ainda nas cidades brasileiras inúmeros edifícios e terrenos públicos abandonados. Disso resulta uma quantidade significativa de imóveis vazios e subutilizados em áreas bem localizadas, com boa infraestrutura, ideais para abrigar unidades habitacionais.

Dois trágicos acontecimentos recentes simbolizam o tipo de problema que emerge do tratamento inadequado da questão habitacional e do descaso com moradores de baixa renda em grandes cidades: o incêndio da Grenfell Tower, em Londres, em 2017, e o incêndio, seguido do desabamento do edifício Wilton Paes de Almeida, em São Paulo, em 2018. No primeiro caso, tratava-se de um prédio de apartamentos para habitação social, inaugurado em 1974. Há indícios de que os materiais de isolamento e os painéis de alumínio utilizados em reforma recente no edifício não eram seguros para esse fim justamente por permitirem rápida expansão do fogo. (EL PAÍS, 2017) 72 pessoas morreram na tragédia. (BBC, 2018) Alguns analistas associam o ocorrido ao descaso das autoridades com as habitações sociais na Grã-Bretanha nas últimas décadas. (LAMMY, 2018) O segundo caso se refere a um edifício comercial inaugurado em 1968, que foi sede de algumas empresas e, posteriormente, de órgãos governamentais. Pertencia à união e passou à condiçáo de desocupado em 2003. Desde meados desta década, abrigava pessoas que tinham estabelecido ali uma ocupação para fins de moradia. De acordo com a Uniáo, tanto a prefeitura quanto ela buscavam a "reintegração amigável do edifício". (G1, 2018) O incêndio começou em um dos andares 
e se espalhou rapidamente pelo edifício, que acabou desabando. Uma semana após o acidente, o Corpo de Bombeiros tinha confirmado uma morte e sete desaparecidos. $(\mathrm{G} 1,2018)$

A crise habitacional, como todas as crises, não afeta todos os habitantes da cidade da mesma forma. Entre os mais vulneráveis estão os menos escolarizados, com menos laços comunitários, em situação irregular no país, condiçóes essas que por vezes se superpóem. Entre esses, muitos trabalham na informalidade. Ao se pensar as condiçóes de vulnerabilidade, há ainda que se levar em consideração questóes referentes a gênero, raça e sexualidade.

A questão do custo do habitar é um dos principais impedimentos no que se refere ao acesso. As condiçóes acima citadas - que certamente não esgotam os fatores de vulnerabilidade - estão ligadas à possibilidade limitada de auferir rendimentos compatíveis com o custeio de uma moradia de qualidade. Alugar ou financiar um imóvel em boas condiçôes se torna algo inatingível.

Entretanto, o rendimento não é o único limitador nesses casos. Existem várias pré-condiçôes quando se trata de acessar o mercado formal de locação ou financiamento de imóveis. Uma série de documentos é exigida, a começar por comprovantes de renda. Isso sem levar em consideração, no caso da locação, a exigência de um ou mais fiadores, pagamento de seguro fiança, ou de depósito caução. Ou seja, é necessário: ter emprego formal ou alguma fonte de renda que permita comprovação; ter condiçóes de poupar ou emprestar recursos de terceiros para o depósito ou o seguro fiança; e/ou contar com pessoas que aceitem a condição de fiador.
Imigrantes e refugiados em situação irregular no país enfrentam vários empecilhos nesse sentido. As barreiras linguísticas, por sua vez, atrapalham até mesmo aqueles em melhores condiçôes. Uma política habitacional em nível local que atenda a população de baixa renda e seja inclusiva em relação a imigrantes e refugiados deve levar em consideração esses fatores.

Aumentar o estoque de habitação acessível e bem localizada - o que pode se dar por meio de programas de financiamento adequados às faixas de renda mais baixas, investimento em unidades para locação social, e readequação, para fins de moradia, de imóveis abandonados, entre outras medidas -, é uma forma mais geral de lidar com o déficit habitacional que impacta positivamente a população mais vulnerável, incluindo os imigrantes e refugiados.

Há que se somar a isso, no entanto, estratégias que foquem especificamente nas dificuldades encontradas por imigrantes e refugiados em situação irregular. Assim como o Sistema Único de Saúde brasileiro atende a todos, sem exceção, também se pode pensar em uma política universalista de habitação que ofereça vagas em abrigos e moradias para essa população impossibilitada de acessar o mercado formal de habitação.

É fundamental que esse tipo de solução habitacional seja bem localizada, próxima a zonas onde as possibilidades de garantir algum tipo de renda são maiores, especialmente regióes centrais.

No caso de abrigos temporários, contornar a resistência que os moradores costumam apresentar diante da possibilidade de sua instalação em seus bairros é tarefa difícil e depende de um longo trabalho que 
leve em conta a posição e as necessidades dos habitantes da vizinhança. $\mathrm{O}$ estabelecimento de certas contrapartidas, um trabalho sério de sensibilização para o problema e promoção de encontros com os recém-chegados são apenas alguns dos caminhos possíveis para a sustentabilidade dessas iniciativas.

É comum que uma série de instituiçôes de apoio a imigrantes e refugiados operem nas cidades que os recebem. Há nelas um saber acumulado sobre as especificidades dessa população e uma capilaridade no seu atendimento que não podem ser desprezados pelo poder público. Nesse sentido, apoiar instituiçôes que dão suporte a imigrantes e refugiados e trabalhar em conjunto com elas é um passo incontornável de uma política de atendimento a esses grupos.

\section{Trabalho e espaços públicos}

Tão comum como a crise habitacional nas cidades que concentram riquezas e oportunidades é a presença de vendedores de rua nas áreas mais movimentadas. Artesanato, brinquedos, alimentos, aparelhos eletrônicos, acessórios para celular, roupas, sapatos e etc. Tudo isso e mais um pouco pode ser encontrado nas calçadas, praças e calçadóes das mais vibrantes cidades do mundo. Esse tipo de atividade, em grande parte informal, está presente mesmo em locais com altas taxas de formalização do emprego.

As razóes que levam trabalhadores a vender mercadorias nas ruas são variadas. É inegável, entretanto, que altas taxas de desemprego forçam muitas pessoas a trabalhar de modo informal. Essa é também a saída encontrada por muitos imigrantes e refugiados sem visto de trabalho no país em que residem. As ruas e calçadas se tornam o lugar da reprodução da vida para muitos dos membros mais vulneráveis da sociedade em lugares tão diversos como Sáo Paulo, Los Angeles e Roma.
No Brasil, a crise econômica que vem assolando o país elevou a taxa de desemprego, que, de acordo com o IBGE, passou de 8,5\% em 2015 a 12,7\% em 2017. Com isso, cresceu também o número de pessoas vendendo produtos nas ruas. Levantamento do IBGE, a pedido do jornal Folha de São Paulo, mostrou que o número de pessoas vendendo alimentos nas ruas subiu de pouco menos de 100 mil pessoas em 2015 para mais de 500 mil pessoas em 2017. (CUNHA, 2018)

Como no caso da questão habitacional, grupos com diferentes características são atingidos de forma desigual pela crise. Embora a classe média, mesmo em seus extratos mais altos, tenha sido também atingida pela crise e pelo desemprego, a rede de contatos e assistência faz com que as perdas objetivas sejam minimizadas. Trabalhadores pobres, sem laços familiares, vivendo em cidades muito distantes de seu local de origem são aqueles para quem a perda de um posto de trabalho pode significar muito rapidamente a perda da moradia e das condiçóes mínimas de sustento. Essa situação é ainda mais grave para imigrantes e refugiados que, além de contar com uma rede limitada de suporte, por vezes não dominam o idioma local e se encontram em situação irregular. Retornar ao local de origem, mesmo quando é uma opção desejável, torna-se também um desafio.

No começo desta década, assistiu-se a uma nova onda migratória para o país. Fugindo de situaçóes adversas de diferentes naturezas e atraídos pelo bom clima econômico do Brasil, senegaleses, haitianos, sírios, venezuelanos, entre outros, desembarcaram aqui com expectativas e perspectivas positivas. Rapidamente, no entanto, a crise econômica que se instalou significou uma profunda insegurança para esses grupos. Além da falta de trabalho, passaram a sofrer ainda mais com o racismo e a xenofobia. Muitos hoje trabalham como ambulantes, mesmo aqueles que tinham conseguido trabalhar por um tempo no comércio, nos serviços e na indústria. 
Embora as regras variem muito de cidade para cidade, em geral há uma série de limitaçôes oficiais à atividade dos vendedores ambulantes. Existem licenças e delimitação de espaços onde se pode trabalhar dessa forma. Em Nova York, onde se estima que haja pelo menos 20 mil vendedores de rua, sua imensa maioria trabalha de forma irregular, uma vez que a legislação limita as licenças para vendedores de rua de mercadorias em geral a 853 e para vendedores de alimentos a mais ou menos 5100. (CITY OF NEW YORK) Assim, grande parte desses trabalhadores se vê submetida a situaçóes adversas como pesadas multas e intimidação policial. (POON, 2015)

A cidade de Los Angeles, conhecida por sua diversidade cultural e por abrigar muitos imigrantes vindos de diferentes partes da América Latina, foi por muitos anos uma das únicas grandes cidades dos EUA em que ser vendedor ambulante era considerado atividade ilegal. Esse tipo de vendedor era considerado contraventor estava sujeito à detenção. Após anos de debate, apenas em abril de 2018 a atividade foi descriminalizada. A pressão para que isso ocorresse se intensificou com a crescente ameaça de deportação de imigrantes desde o início do governo de Donald Trump, em janeiro de $2017^{8}$.

No Brasil, muitas vezes os governos locais optam pela criação de centros comerciais, comumente chamados de shoppings populares ou camelódromos, com vistas a solucionar a questáo do espaço de trabalho dos vendedores ambulantes. Essas iniciativas são bastante utilizadas no âmbito de projetos de revitalização de regióes centrais degradadas com potencial turístico em virtude de uma arquitetura à qual se atribui valor histórico. (JAYME, NEVES, 2010).

Não raro, emergem aqui e alhures notícias sobre abordagens violentas de vendedores ambulantes perpetradas por agentes estatais. São comuns também contendas entre os próprios ambulantes, que têm de disputar cotidianamente os melhores pontos de venda.

Náo parece exagerado afirmar, pois, que o maior problema enfrentado pelos vendedores ambulantes é sua condição irregular, pois ficam sujeitos a perder sua mercadoria e mesmo sofrer violência por parte de agentes do Estado responsáveis pelo cumprimento das normas.

Em estudo sobre a saúde física e mental de trabalhadores ambulantes, Santos e Mesquita (2016) mencionam ainda os problemas advindos do fato de exercerem suas atividades em locais com pouca higiene, sem banheiro, e sem proteçáo do frio, do calor e da chuva. A isso soma-se o medo de assaltos.

A essas dificuldades, há que se adicionar ainda fatores como: a falta de um local adequado para armazenamento de suas mercadorias e para a preparação de bebidas e alimentos; dificuldade em se alimentar de forma adequada e a preços acessíveis; e falta de acesso a fontes de água potável.

Diante desse cenário, cabe perguntar que tipo de espaço público se deseja e que medidas tomar para se aproximar dele, levando em consideração as especificidades da população que atua no comércio ambulante.

Propóe-se aqui que os governos locais sejam, em primeiro lugar, sensíveis às razôes que levam à existência do comércio ambulante. Altas taxas de desemprego e a impossibilidade de se inserir no mercado de trabalho formal por limitaçôes referentes a vistos de trabalho são apenas algumas delas. A repressão pura e simples aos vendedores em situação irregular é inócua, na medida em que não lida minimamente com as condiçóes que produzem esse tipo de realidade. Com isso, produz-se ainda mais desigualdade, uma vez que se oprime os mais vulneráveis.

Como no caso da habitação, medidas de caráter estrutural, como o estímulo à criação de postos de trabalho formais, são formas de melhorar as condiçóes de vida dos trabalhadores pobres e menos escolarizados. Certamente uma parte significativa dos trabalhadores informais desejaria a condição mais estável de trabalhador com carteira assinada. Entretanto, a 
possibilidade de ação dos governos locais é bastante limitada nesse sentido, uma vez que a criação de empregos está muito ligada à política econômica definida em âmbito federal/nacional. Além disso, como se mencionou na introdução deste trabalho, em geral não é da alçada do governo local conceder permissóes de trabalho a moradores de outras nacionalidades. Assim, ainda que no âmbito da cidade se consiga resultados positivos em termos de formalização do trabalho, imigrantes e refugiados em situaçáo irregular seguirão à margem.

Independentemente do sucesso de uma política de estímulo à abertura de postos de trabalho com carteira assinada, o fato é que, em grandes cidades, os governos locais sempre terão de lidar com um contingente significativo de vendedores de rua. Se a intenção é melhorar sua condição de vida, um ponto fulcral é impedir as abordagens violentas por parte dos agentes responsáveis pela fiscalização das ruas. Isso leva necessariamente a buscar caminhos para a regularização desses trabalhadores, de modo que não fiquem expostos à intimidação policial.

Outras iniciativas de cunho mais prático podem melhorar sobremaneira as condiçôes de vida desses trabalhadores. Tomando como ponto de partida os problemas aventados anteriormente, pode-se pensar em medidas como: a criação de depósitos seguros e bem localizados para o armazenamento de mercadorias, que podem também contar com vestiários; construção de cozinhas coletivas com equipamentos apropriados e condiçóes adequadas de higiene e segurança, onde se poderia inclusive fazer a capacitação dos trabalhadores; e instalação de mais banheiros públicos e bebedouros que pudessem atender não só esses trabalhadores, mas também os transeuntes em geral. Outra medida interessante seria a criação de equipes de saúde que atendessem esses trabalhadores nos locais onde estabelecem seus pontos de venda.

Do ponto de vista urbanístico, além da instalação dos equipamentos citados acima, há que se pensar na qualidade dos espaços públicos, especialmente pra- ças e calçadas. Isso inclui: boa pavimentação; arborização; e elementos de mobiliário urbano (bancos, quiosques, paraciclos, guarda corpos, entre outros), além dos já mencionados acima, projetados levando em consideração as necessidades de quem trabalha na rua.

Para o caso específico dos imigrantes e refugiados, faz-se necessário disponibilizar intérpretes que os ajudem a compreender a burocracia local e buscar auxílio em situações adversas. Assim como no caso da habitação, uma boa estratégia é estabelecer parceria com instituiçóes que já trabalham junto a essa população.

Não se pode esquecer que qualquer desenho de política não pode prescindir de um trabalho sério de pesquisa, conduzido por uma equipe interdisciplinar, que investigue o perfil do ambulante para buscar as melhores estratégias para lidar com suas necessidades.

\section{Consideraçóes finais}

É importante ressaltar que o tema da imigração, associado às questôes de habitação e trabalho, foi tratado aqui de forma bastante superficial. Cada um dos tópicos aventados merece um estudo mais aprofundado, dada a sua centralidade para pensar o tipo de cidade que se deseja construir e o tipo de ser humano que se deseja fazer surgir. Tal firmação, um tanto exagerada, inspira-se na reflexão de Park sobre a cidade. Nas palavras do autor, a cidade é

(...)"no geral, a tentativa mais consistente do ser humano de reconstruir o mundo em que viver de acordo com o seu desejo. No entanto, se a cidade é o mundo que o ser humano construiu, ela é também o mundo em que ele está condenado a viver a partir de entấo. Dessa forma, indiretamente, e sem uma noção clara da natureza dessa tarefa, ao fazer a cidade o 
ser humano se reconstruiu a si mesmo?. (PARK, 1967,p.3, tradução nossa).

Não há como negar que o "partido"- para adotar o jargáo de profissionais da arquitetura- deste texto é deveras normativo e tem a ver com a defesa de um tipo de política urbana que tenha como princípios fundamentais a efetivação do direito à moradia e o acolhimento das diferenças.

Acredita-se qua as trocas de saberes e modos de vida proporcionadas pelos movimentos migratórios enriquece a cidade de diversas maneiras, inclusive do ponto de vista econômico. Levando-se em consideração temasrelacionados à política e à cidadania, cabe acrescentar que as lutas dos trabalhadores informais e sem permissão para trabalhar têm muito a contribuir em termos de formas de organização e demandas de direitos,como atesta uma série de pesquisas sobre os movimentos sociais que envolvem esses atores.(cf. BHIMJ,2010;ROSALES,2013).

A reflexão de Caldeiras (2000) sobre a cidade moderna é extremamente últil para pensar os caminhos para a produçáo de uma cidade em que todos os residentes, independentemente, de suas características, possam negociarr, em pé de igualdade, as condiçóes que regem a vida naquele espaço. Segunda a autora,

“[os] ideais de política democrática-abertura, indeterminação, fluidez e coexistência de diferenças não assimiladasencontraram algumas de suas melhores expressōes nos espaços públicos das cidades modernas. Estes espaços promovem interações entre pessoas que são forçadas a confrontar seus anonimatos e os dos outros com base na cidadania e assim a reconhecer e respeitar os direitos iguais do outro. É claro que há várias maneiras de suberter aquela igualdade e invocar diferenças de status e hierarquias. No entanto, o espaço da cidade moderna, mais que qualquer outro, força esse confronto e conseguentem entetem o pontecial de desafiar e nivelar essas hierarquias. No espaço da cidade moderna diferentes cidadãos negociam os termos de suas interaçôes e de fato interagem socialmente a despeito de suas diferenças e desigualdades. Esse ideal de cidade aberta às diferenças e negociaçóes em encontros anônimos cristaliza o (...) espaço público moderno e democrático". (CALDEIRA,2000, p.307,grifos nossos).

Defende-se aqui, por fim, a ideia de que a política urbana só será capaz de produzir esse espaço público democrático se partir da simples e potente premissa de que "nenhum ser humano é ilegal" 10 .

\section{Notas de fim:}

1. De acordo com o Comitê Nacional para Refugiados (CONARE), órgáo multiministerial do qual participam o governo, a sociedade civil e a ONU, por meio do ACNUR, refugiado é a "pessoa que deixa o seu país de origem ou de residência habitual devido a fundado temor de perseguição por motivos de raça, religião, nacionalidade, grupo social ou opinióes políticas, como também devido à grave e generalizada violação de direitos humanos, e não possa ou não queira acolher-se da proteção de tal país." (CONARE).

2. Nos EUA, isso se deu de forma ainda mais acirrasa devido à flexibilização das normas de operação do mercado financeiro, especialmente ao longo dos anos 1990 e 2000. 
3. Sobre isso, ver SANTOS et al.,20016

4. Instituição responsável pelo cálculo do déficit habitacional no Brasil, a partir de microdados da Pinad ( pesquisa nacional de domićlios do IBGE).

5. O conceito de déficit habitacional utilizado pela Fundação João Pinheiro está ligado diretamente ás deficiências do estoque de moradias. "Engloba aquelas sem condição de serem habitadas em razão da precariedade das construçôes ou do desgaste da estrutura física e que por isso devem ser repostas. Inclui ainda a necessidade de incremento do estoque, em função da coabitação familiar forçada (famílias que pretendem constituir um domicilio unifamiliar), dos moradores de baixa renda cpm dificuldade de pagar aluguel nas áreas urbanas e dos que vivem em casas e apartamentos algugados com grande densidade. Inclui-se ainda nessa rubrica a moradia em imóveis e locais com fins não residenciais. $\mathrm{O}$ déficit habitacional pode ser entendido, portanto, como déficit por reposição de estoque e déficit por incremento de estoque."(FUNDAÇÃO JOÃO PINHEIRO, 2018, p.20).

6. O ônus excessivo com aluguel urbano "corresponde ao número de famílias urbanas com renda familiar de até três salários mínimos que moram em casa ou apartamento(domicílios urbanos duráveis) e que despendem mais de $30 \%$ de sua renda com aluguel."

7. Em Inglês, há até memso um acrônico(NIMBY= not in my backyard, em tradução, não no meu quintal) para descrever a reação de moradores a instação de equipamentos indesejados na sua vizinhança, que vão desde aeroportos e shopping centers até grandes conjuntos habitacionais e abrigos para imigrantes e refugiados.

8. A proposta de descriminalização dos vendedores ambulantes apresentada ao conselho da cidade de Los Angeles mencionava a intenção expressa do presidente Donald Trump de deportar imigrantes com ficha criminal que estão no país de forma ilegal e afirmava que "seguir impondo penas de delito criminal pela atividade de vendedor ambulante afeta e desproporcionalmente e pune injustamente imigrantes sem documento e os coloca potencialmente em risco de serem deportados". (NBCLA,2017).
9. O texto em língua estrangeira é "man’s most consistent and on the whole, his most successful attempt to remake the world he lives in more after his heart's desire. But, if the city is the world which man created, it is the world in which he is henceforth condemned to live. Thus, indirectly, and without any clear sense of the nature of his task, in making the city man has remade himself."

10. Frase do sobrevivente do Holocausto e ganhador do prêmio Nobel da Paz, Elie Wiesel, e que tem sido bastante citada no debate recente sobre imigração nos EUA.

\section{Referências Bibliográficas}

ALBERS, M. (2016). The financialisation of housing. A political economy approach. Oxon: Routledge.

BBC. (2018). What happened at Grenfell Tower Disponível em: http://www.bbc.com/news/uk-england-london-40272168. Acesso em 27 de maio de 2018.

BESWICK, J. et al. (2016). Speculating on London's housing future. City, 20(2), 321-341.

BHIMJI, F. (2010). Struggles, Urban Citizenship, And Belonging: The Experience Of Undocumented Street Vendors And Food Truck Owners In Los Angeles. Urban Anthropology and Studies of Cultural Systems and World Economic Development, 39(4), 455-492.

BRENNER, N., THEODORE, N. (2002). Cities and the Geographies of "Actually Existing Neoliberalism." Antipode, 34(3), 349-379.

CARVALHO, A. P. (2016). Estatuto da Cidade e Juridificação da Reforma Urbana no Brasil. Rio de Janeiro: Contra Capa.

CASTRO, D., NOVAES, P. (2015). Copa do Mundo 2014 e os Impactos no Direito à Moradia: uma análise das cidades-sede brasileiras. In Brasil: os impactos da Copa do Mundo 2014 e das Olimpíadas 2016. Rio de Janeiro: E-papers.

CITY OF NEW YORK, Street vending. Disponível em: http://www.nyc.gov/html/sbs/nycbiz/downloads/pdf/ educational/sector_guides/street_vending.pdf. Acesso em 27 de maio de 2018. 
CUNHA, J. (2018). Meio milhão de brasileiros vendem comida na rua. FOLHA DE SÃO PAULO. Disponível em: http://www1.folha.uol.com.br/mercado/2018/01/ 1948561-meio-milhao-de-brasileiros-vende-comida-na-rua.shtml. Acesso em 27 de maio de 2018.

EL PAÍS. (2017). Uma geladeira, a origem do incêndio da torre Grenfell de Londres. Disponível em: https://brasil.elpais.com/brasil/2017/06/23/internacional/1498211257_235698.html. Acesso em 27 de maio de 2018 .

ELGOT, J. (2017). Theresa May to unveil plan for "rebirth" in council housing in conference speech. The Guardian. Disponível em: http://www.theguardian.com/politics/2017/ oct/04/theresa-may-to-unveil-plan-for-rebirth-in-council-housing-in-conference-speech. Acesso em 27 de maio de 2018.

FARHA, L. (2017). Report of the Special Rapporteur on adequate housing as a component of the right to an adequate standard of living, and on the right to non-discrimination in this context: Financialization of housing and the right to adequate housing. Geneva: United Nations Office of the High Commissioner on Human Rights. Apud FIELDS, D. J., HODKINSON, S. N. (2018). Housing Policy in Crisis: An International Perspective. Housing Policy Debate, 28(1), 1-5.

FIELDS, D. J., HODKINSON, S. N. (2018). Housing Policy in Crisis: An International Perspective. Housing Policy Debate, 28(1), 1-5.

FUNDAÇÃO JOÁO PINHEIRO. (2018). Déficit habitacional no Brasil 2015, Belo Horizonte : FJP.

HARVEY, D. (1996). Do gerenciamento ao empresariamento: a transformação da administração urbana no capitalismo tardio. Espaço \& Debates. Revista de Estudos Regionais e Urbanos, (39), 48-64.

G1 (2018) Sobe para 7 o número de desaparecidos no desabamento do prédio no Centro de SP. Disponível em: https://g1.globo.com/sp/sao-paulo/noticia/sobe-para-7-o-numero-de-desaparecidos-no-desabamento-do-predio-no-centro-de-sp.ghtml. Acesso em 27 de maio de 2018.

JAYME, J., NEVES, M. (2010). CIDADE E ESPAÇO PÚBLICO: política de revitalização urbana em Belo Horizonte. Caderno CRH, 23(60).
KNIGHT FRANK (2015) Global Development Report 2015: Prime Residential Development Trends and Insight, http://www.knightfrank.com/research/global-development-report-2015-3229.aspx. Apud BESWICK, J. et al. (2016). Speculating on London's housing future. City, 20(2), 321-341.

LAMMY, D. (2017). Those responsible for the horror of the Grenfell Tower fire must face trial | David Lammy. The Guardian. Disponível em: http://www.theguardian.com/ commentisfree/2017/dec/26/grenfell-tower-fire-david-lammy. Acesso em 27 de maio de 2018.

NBCLA (2017) Los Angeles City Council Votes to Legalize Street Vending. Disponível em: https://www.nbclosangeles.com/news/local/Los-Angeles-City-Council-street-vendors-decriminalize-ordinance-412254193.html. Acesso em 27 de maio de 2018.

PARK, Robert (1967). On Social Control and Collective Behavior. Chicago: University of Chicago Press.

POON, L. (2015). What Street Vendors Look Like Around The World. Disponível em: http://www.citylab.com/ work/2015/11/a-look-at-street-vendors-around-the-world/415722/. Acesso em 27 de maio de 2018.

ROLNIK, R. (2014). Report of the Special Rapporteur on adequate housing as a component of the right to an adequate standard of living, and on the right to non-discrimination in this context: Guiding Principles on security of tenure for the urban poor. Geneva: United Nations Office of the High Commissioner on Human Rights. Apud FIELDS, D. J., HODKINSON, S. N. (2018). Housing Policy in Crisis: An International Perspective. Housing Policy Debate, 28(1), 1-5.

et al. (2015). O Programa Minha Casa Minha Vida nas regióes metropolitanas de São Paulo e Campinas: aspectos socioespaciais e segregação. Cadernos Metrópole, 17(33), 127-154.

ROSALES, R. (2013). Survival, Economic Mobility and Community among Los Angeles Fruit Vendors. Journal of Ethnic and Migration Studies, 39.

SANTOS, D. R. DOS, MESQUITA, A. A. (2016). Avaliação das condiçóes de trabalho e sofrimento psíquico em camelôs. Revista Psicologia e Saúde, 8(2), 29-42. 